\title{
EDITORIAL
}

\section{DEFINING UNDERNUTRITION (MALNUTRITION) IN OLDER PERSONS}

\author{
J.E. MORLEY
}

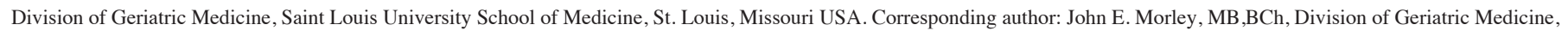
Saint Louis University School of Medicine, 1402 S. Grand Blvd., M238, St. Louis, MO 63104, Email: john.morley@health.slu.edu

The Four major parenteral and enteral nutrition societies, viz Europe (ESPEN), USA (ASPEN), Asia (PENSA) and Latin America (FELANPE), are attempting to develop a global consensus on diagnostic criteria for malnutrition (1). This has been driven to some extent by the fact that confusion exists among dietitians and other health professionals regarding the use of terminology such as malnutrition, starvation, cachexia and sarcopenia (2). The World Health Organization defines malnutrition as deficiencies, excesses or imbalances in a person's intake of energy and/or nutrients. They identify two broad groups of malnutrition, the one being undernutrition and the other being over nutrition (www.who.int/features/qu/ malnutrition/en/; accessed October 20, 2017). Unfortunately, the ESPEN guidelines while recognizing that malnutrition is a broader concept, also uses it to describe undernutrition (which they recognize as a synonym) (3). One hopes that as these guidelines develop they will use either undernutrition alone or protein energy malnutrition to identify nutrition problems associated with loss of weight.

The next problem is that the criteria for diagnosing malnutrition as being reduced body mass index (BMI) $(<18.5$ $\mathrm{kg} / \mathrm{cm} 2$ ) or weight loss and reduced BMI or loss of free fat mass. The problem with this definition is it fails to distinguish it from loss of body parts (amputation) or from cachexia. The ASPEN malnutrition criteria requires any 2 of low energy intake, weight loss, loss of muscle mass, loss of subcutaneous fat mass, fluid accumulation on hand grip strength (4). This definition has the same problems as the ESPEN criteria but also would include persons with age-related sarcopenia (loss of muscle mass and low handgrip strength). Thus, we would argue that the societies should use the weight loss $(>5 \%$ in 6 months) that does not occur in the situation where the person is not undergoing appropriate therapeutic dieting as an umbrella term for undernutrition and cachexia (Figure 1). While weight loss leads to the loss of muscle mass leading to sarcopenia, most persons with sarcopenia do not have excess weight loss as muscle loss is replaced by fat (5-8). Both weight loss and sarcopenia are major causes of the physical phenotype of frailty, but frailty should be considered a secondary nutritional condition (9-16).

Undernutrition can be considered to be a condition in which inadequate calories are being delivered to the portal blood system, which is correctable either by correcting the cause or providing enteral or parental nutritional support. The major cause of undernutrition remains worldwide to be unavailability

of an adequate food supply leading to starvation (marasmus) (17). Inappropriate dieting as occurs in anorexia nervosa and in older persons who excessively calorically restrict leads to loss of muscle and bone and is another obvious cause of undernutrition. Intentional weight loss in older persons leads to loss of muscle and bone as well as increased circulating toxins and fatty acids which have been associated with early mortality (18-22). Many older persons develop an anorexia of aging (2325). This can be aggravated by medications, depression, elder abuse, late life paranoia, swallowing problems, oral problems, nosocomial infections, e.g., Helicobacter pylori, dementia, endocrine disorders (e.g., Addison's disease, hypercalcemia), delayed stomach emptying, diabetes mellitus, therapeutic diets, low grade inflammation associated with arthritis and excess adipose tissue and dyspnea associated with hypoxia when eating in persons with COPD (26-30).

Figure 1

Causes and Outcome of Weight Loss in Older Persons

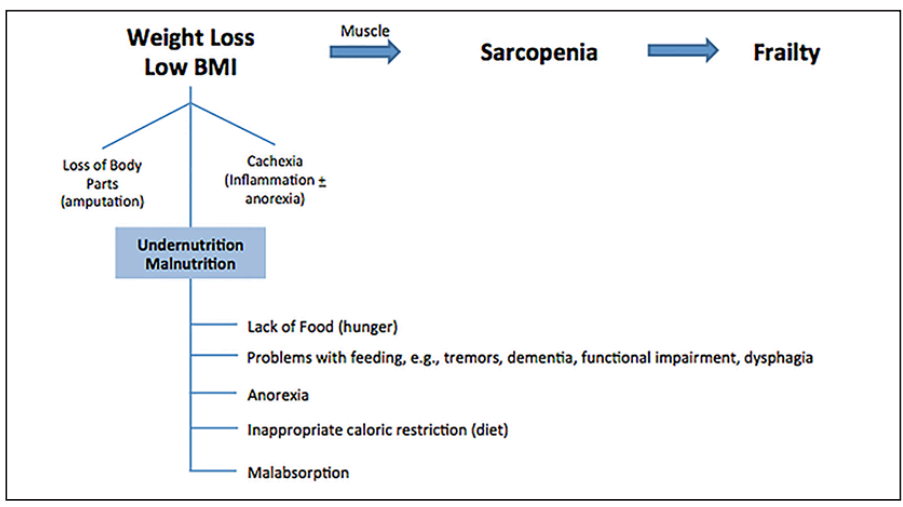

Numerous mechanical problems with feeding occur in older persons. These include tremors in Parkinson's disease, functional impairment, dysphagia and dementia. Inability of persons with dementia to remember to eat is a not uncommon cause of weight loss (31). Feeding a person with dementia can take up to 40 minutes a meal (32). Persons with Parkinson's disease may benefit from a computer regulated stabilizing spoon (www.liftware.com). Dysphagia is an interesting example of a mechanical problem (33-35). Dysphagia leads to a decrease in food intake and through aspiration pneumonia an increase in inflammatory cytokines. Increased inflammatory cytokines lead both to anorexia but also to muscle mass loss leading to sarcopenia (Figure 2) (36-38). 


\section{THE JOURNAL OF NUTRITION, HEALTH \& AGINGC}

Figure 2

Mechanisms by which Dysphagia Causes Undernutrition and Sarcopenia

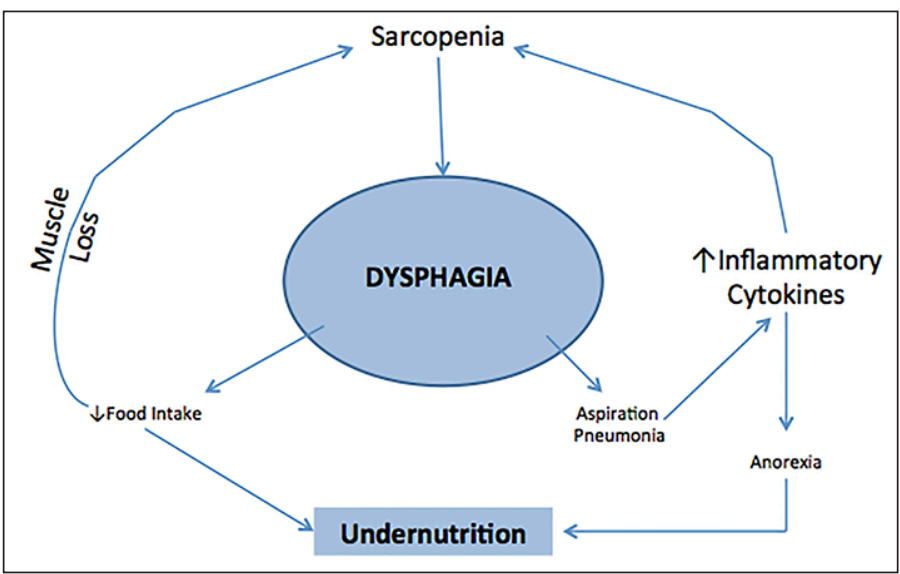

Finally malabsorption, such as gluten enteropathy and pancreatic insufficiency, are not rare in older persons resulting in undernutrition (39).

When persons are at risk for undernutrition they should be administered validated nutritional screening tools. The Simplified Nutritional Appetite Questionnaire (SNAQ) has been shown to be an excellent tool to identify persons at risk of weight loss (40-43). The MiniNutritional Assessment MNA) and its short form have been well validated for use in older populations to identify those at risk (44-49). However, it needs to be recognized that the MNA also is likely to identify persons at risk for frailty (50). Other screening tools that are commonly used are the Nutrition Risk Screening 2002 and the Malnutrition Universal Screening Tool (MUST) $(51,52)$. Albumin and prealbumin should not be used as nutritional screening tools (53).

Whether or not cachexia should be considered a nutritional disorder remains open for discussion. While undernutrition can, for the most part, be reversed with nutrition, it is much less clear what the role of nutrition is during the cachexia process (54). Cachexia is defined as a loss of lean mass due to inflammatory cytokines $(55,56)$. It also has anorexia, anemia, and low albumin (57). Persons with cachexia have a loss of muscle out of proportion to fat loss. The loss of albumin is due mainly to third spacing secondary to inflammation and not due to poor intake. Kwasiorkor occurs in starving children when they become infected (55). In the "Society of Sarcopenia, Cachexia and Wasting Disorders" guidelines it is specifically stated that "cachexia is often incorrectly perceived as malnutrition' (56). Diagnosis of cachexia can be made when weight loss is accompanied by a CRP level $>5 \mathrm{mg} / \mathrm{L}$ (58). Overall, the treatment of cachexia is the treatment of the underlying disease. Exercise and protein supplementation may play a role in preserving muscle mass and improving quality of life during the treatment of the underlying disease.

In conclusion, early recognition of anorexia and subsequent weight loss is important in the care of older persons. Undernutrition is an important cause of sarcopenia and frailty in older persons, suggesting that they should be screened for at the same time as using validated nutritional risk screening tools. The Rapid Geriatric Assessment (RGA) tool is a rapid method by which this can be done (59). There are numerous treatable causes of weight loss in older persons and these can be recognized using the "MEALS-ON-WHEELS" mnemonic (Table 1) (60). A CRP level should be obtained to rule out cachexia in person with rapid weight loss.

Table 1

MEALS-ON-WHEELS Mnemonic for Treatable Causes of Weight Loss in Older Persons

Medications (e.g., digoxin, theophylline, cimetidine)

Emotional (e.g., depression)

Alcoholism, elder abuse, anorexia tardive

Late life paranoia

Swallowing problems

Oral factors

Nosocomial infections (e.g., tuberculosis)

Wandering and other dementia related factors

Hyperthyroidism, Hypercalcemia, Hypoadrenalism

Enteral problems (e.g., gluten enteropathy)

Eating problems

Low salt, low cholesterol and other therapeutic diets

Stones (cholecystitis)

\section{References}

1. Cederholm T, Jensen GL. To create a consensus on malnutrition diagnostic criteria: A report from the Global Leadership Initiative on Malnutrition (GLIM) meeting at the ESPEN Congress 2016. Clin Nutr 2017;36:7-10.

2. Ter Beek L, Vanhauwaert E, Slinde F, Orrevall Y, Henriksen C, Johansson M, et al Unsatisfactory knowledge and use of terminology regarding malnutrition, starvation, cachexia and sarcopenia among dietitians. Clin Nutr 2016;35:1450-1456.

3. Cederholm T, Barazzoni R, Austin P, Ballmer P, Biolo G, Bischoff SC, et al. ESPEN guidelines on definitions and terminology of clinical nutrition. Clin Nutr 2017;36:4964

4. White JV, Guenter P, Jensen G, Malone A, Schofield M. Consensus statement: Academy of Nutrition and Dietetics and American Society for Parenteral and Enteral Nutrition: Characteristics recommended for the identification and documentation of adult malnutrition (undernutrition). JPEN J Parenter Enter Nutr 2012;36:275-283.

5. Steffl M, Musalek M, Kramperova V, Petr M, Kohlikova E, Holmerova I, Volicer 


\section{DEFINING UNDERNUTRITION (MALNUTRITION) IN OLDER PERSONS}

L. Assessment of diagnostics tools for sarcopenia severity using the item response theory (IRT). J Nutr Health Aging 2016;20:1051-1055.

6. Yadigar S, Yavuzer H, Yavuzer S, Cengiz M, Yuruyen M, Doventas A, Erdincle DS. Primary sarcopenia in older people with normal nutrition. J Nutr Health Aging 2016;20:234-238.

7. Morley JE, Cao L. Rapid screening for sarcopenia. J Cachexia Sarcopenia Muscle 2015;6:312-314

8. McKee A, Morley JE, Matsumoto AM, Vinik A. Sarcopenia: An endocrine disorder? Endocr Pract 2017;23:1140-1149.

9. Morley JE, von Haehling S, Anker SD, Vellas B. From sarcopenia to frailty: A road less traveled. J Cachexia Sarcopenia Muscle 2014;5:5-8.

10. Wei K, Nyunt MSZ, Gao Q, Wee SL, Ng TP. Frailty and malnutrition: Related and distinct syndrome prevalence and association among community-dwelling older adults: Singapore Longitudinal Ageing Studies. J Am Med Dir Assoc 2017;Aug 10. Doi: 10.1016/j.jamda.2017.06.017 [Epub ahead of print].

11. Garcia-Nogueras I, Aranda-Reneo I, Pena-Longobardo LM, Oliva-Moreno J, Abizanda P. Use of health resources and healthcare costs associated with frailty: The FRADEA study. J Nutr Health Aging 2017;21:207-214.

12. Sinclair A, Vellas B. Editorial: Frailty - An emerging high impact complication of diabetes requiring specific management approaches. J Nutr Health Aging 2017;21:193-194.

13. Chan DD, Tsou HH, Chang CB, Yang RS, Tsauo JY, Chen CY, et al. Integrated care for geriatric frailty and sarcopenia: A randomized control trial. J Cachexia Sarcopenia Muscle 2017;8:78-88

14. Dent E, Lien C, Lim WS, Wong WC, Wong CH, Ng TP, Woo J, et al. The AsiaPacific clinical practice guidelines for the management of frailty. J Am Med Dir Assoc 2017;18:564-575.

15. Morley JE. Developing Novel Therapeutic Approaches to Frailty. Curr Pharm Design 2009;15:3384-3395.

16. Malmstrom TK, Miller DK, Morley JE. A comparison of four frailty models. J Am Geriatr Soc 2014;62:721-726.

17. Morley JE. Undernutrition in older adults. Fam Pract 2012;29(Suppl 1):i89-i93.

18. Weiss EP, Jordan RC, Frese EM, Albert SG, Villareal DT. Effects of weight loss on lean mass, strength, bone, and aerobic capacity. Med Sci Sports Exerc 2017;49:206 217

19. Villareal DT, Fontana L, Das SK, Redman L, Smith SR, Saltzman E, et al. Effect of two-year caloric restriction on bone metabolism and bone mineral density in nonobese younger adults: A randomized clinical trial. J Bone Miner Res 2016;31:40-51.

20. Soenen S, Chapman IM. Body weight, anorexia, and undernutrition in older people. J Am Med Dir Assoc 2013;14:642-648.

21. Landi F, Liperoti R, Lattanzio F, Russo A, Tosato M, Barillaro C, Bernabei R, Onder G. Effects of anorexia on mortality among older adults receiving home care: An observation study. J Nutr Health Aging 2012;16:79-83.

22. Mir F, Zafar F, Morley JE. Anorexia of aging: Can we decrease protein energy undernutrition in the nursing home? J Am Med Dir Assoc 2013;14:77-79.

23. Morley JE. Anorexia of aging: A key component in the pathogenesis of both sarcopenia and cachexia. J Cachexia Sarcopenia Muscle 2017:8:523-526.

24. Morley JE. Anorexia and weight loss in older persons. J Gerontol A Biol Sci Med Sci 2003;58:131-137.

25. Morley JE. Anorexia of aging: A true geriatric syndrome. J Nutr Health Aging 2012;16:422-425

26. Morley JE. Pathophysiology of the anorexia of aging. Curr Opin Clin Nutr Metab Care 2013;16:27-32.

27. Morley JE. Causes of weight loss in a community nursing home. J Am Geriatr Soc $1994 ; 42: 583-585$

28. Tamura BK, Bell CL, Masaki KH, Amella EJ. Factors associated with weight loss, low BMI, and malnutrition among nursing home patients: A systematic review of the literature. J Am Med Dir Assoc 2013;14:649-655.

29. Sanders KJ, Kneppers AE, van de Bool C, Langen RC, Schols AM. Cachexia in chronic obstructive pulmonary disease: New insights and therapeutic perspective. J Cachexia Sarcopenia Muscle 2016;7:5-22.

30. van de Bool C, Rutten EPA, van Helvoort A, Franssen FME, Wouters EFM, Schols AMWJ. A randomized clinical trial investigating the efficacy of targeted nutrition as adjunct to exercise training in COPD. J Cachexia Sarcopenia Muscle 2017; Jun 12 doi: $10.1002 /$ jcsm.12219 [Epub ahead of print].

31. Murphy J, Holmes J, Brooks C. Measurements of daily energy intake and total energy expenditure in people with dementia in care homes: The use of wearable technology. J Nutr Health Aging 2017;21:927-932.

32. Simmons SF, Schnelle JF. Feeding assistance needs of long-stay nursing home residents and staff time to provide care. J Am Geriatr Soc 2006;54:919-924.

33. Streicher M, Wirth R, Schindler K, Sieber CC, Hiesmayr M, Volkert D. Dysphagia in nursing homes-results from the NutritionDay project. J Am Med Dir Assoc 2017;Oct 10. Doi: 10.1016/j.jamda.2017.08.015 [Epub ahead of print].

34. Wakabayashi H, Matsushima M. Dysphagia assessed by the 10 -item eating assessment tool is associated with nutritional status and activities of daily living in elderly individuals requiring long-term care. J Nutr Health Aging 2016;20:22-27.

35. Payne MA, Morley JE. Dysphagia: A new geriatric syndrome. J Am Med Dir Assoc $2017 ; 18: 555-557$
36. Yoshimura Y, Wakabayashi H, Bise T, Tanoue M. Prevalence of sarcopenia and its association with activities of daily living and dysphagia in convalescent rehabilitation ward inpatients. Clin Nutr 2017;Sept 23 doi: 10.1016/j.clnu.2017.09.009 [Epub ahead of print].

37. Sakai K, Nakayama E, Tohara H, Kodama K, Takehisa T, Takeshis Y, Ueda K. Relationship between tongue strength, lip strength, and nutrition-related sarcopenia in older rehabilitation inpatients: A cross-sectional study. Clin Interv Aging 2017; 12:1207-1214.

38. Suzuki M, Maeda K, Shamoto H, Wakabayashi $\mathrm{H}$. Effects of aging and sarcopenia on strength of swallowing muscles in older adults. Geriatr Gerontol Int 2017;17:360-361.

39. Mukherjee R, Egbuna I, Brar P, Hernandez L, McMahon DJ, Shane EJ, et al. Celiac disease: Similar presentations in the elderly and young adults. Dig Dis Sci 2010;55:3147-3153.

40. Pilgrim AL, Baylis D, Jameson KA, Cooper C, Sayer AA, Robinson SM, Roberts HC. Measuring appetite with the Simplified Nutritional Appetite Questionnaire identifies hospitalized older people at risk of worse health outcomes. J Nutr Health Aging 2016;20:3-7.

41. Tokudome Y, Okumura K, Kumagai Y, Hirano H, Kim H, Morishita S, Satanabe Y. Development of the Japanese version of the Council on Nutrition Appetite Questionnaire and its simplified versions, and evaluation of their reliability, validity, and reproducibility. J Epidemiol 2017;27:524-530.

42. Rolland Y, Perrin A, Gardette V, Filhol N, Vellas B. Screening older people at risk of malnutrition or malnourished using the Simplified Nutritional Appetite Questionnaire (SNAQ): A comparison with the Mini-Nutritional Assessment (MNA) tool. J Am Med Dir Assoc 2012;13:31-34.

43. Wilson MM, Thomas DR, Rubenstein LZ, Chibnall JT, Anderson S, Baxi A, et al. Appetite assessment: Simple appetite questionnaire predicts weight loss in community-dwelling adults and nursing home residents. Am J Clin Nutr 2005;82:1074-1081.

44. Vellas B, Villars H, Abellan G, Soto ME, Rolland Y, Guigoz Y, et al. Overview of the MNA - its history and challenges. J Nutr Health Aging 2006;10:456-463

45. Lilamand M, Kelaiditi E, Cesari M, Raynaud-Simon A, Ghisolfi A, Guyonnet S, et al; Toulouse Frailty Platform Team. Validation of the mini nutritional assessment-short form in a population of frail elders without disability. Analysis of the Toulouse frailty platform population in 2013. J Nutr Health Aging 2015;19:570-574.

46. Lilamand M, Kelaiditi E, Demougeot L, Rolland Y, Vellas B, Cesari M. The mini nutritional assessment-short form and mortality in nursing home residents - results from the INCUR study. J Nutr Health Aging 2015;19:383-388.

47. Donini LM, Poggiogalle E, Molfino A, Rosano A, Lenzi A, Rossi Fanelli F, Muscaritoli M. Mini-nutritional assessment, malnutrition universal screening tool, and nutrition risk screening tool for the nutritional evaluation of older nursing home residents. J Am Med Dir Assoc 2016;17:959.e11-e18.

48. Win AZ, Ceresa C, Arnold K, Allison TA. High prevalence of malnutrition among elderly veterans in home based primary care. J Nutr Health Aging 2017;21:610-613.

49. Kaiser MJ, Bauer JM, Ramsch C, Uter W, Guigoz Y, Cederholm T, et al. Validation of the Mini Nutritional Assessment short-form (MNA-SF): A practical tool for identification of nutritional status. J Nutr Health Aging 2009;13:782-788.

50. Bollwein J, Volkert D, Diekmann R, Kaiser MJ, Uter W, Vidal K, Sieber CC, Bauer JM. Nutritional status according to the mini nutritional assessment (MNA®) and frailty in community dwelling older persons: A close relationship. J Nutr Health Aging 2013; 17:351-356.

51. Kondrup J, Allison SP, Elia M, Vellas B, Plauth M, Educational and Clinical Practice Committee, European Society of Parenteral and Enteral Nutrition (ESPEN). ESPEN guidelines for nutrition screening 2002. Clin Nutr 2003;22:415-421.

52. Charney P. Nutrition screening vs nutrition assessment: How do they differ? Nutr Clin Pract 2008;23:366-372.

53. Omran ML, Morley JE. Assessment of protein energy malnutrition in older persons, Part II: Laboratory evaluation. Nutrition 2000;16:131-140.

54. Anker SD, Morley JE. Cachexia: A nutritional syndrome? J Cachexia Sarcopenia Muscle 2015;6:269-271.

55. Morley JE, Thomas DR, Wilson MM. Cachexia: Pathophysiology and clinical relevance. Am J Clin Nutr 2006;83:735-743.

56. Evans WJ, Morley JE, Argiles J, Bales C, Baracos V, Guttridge D, Jatoi A, et al Cachexia: A new definition. Clin Nutr 2008;27:793-799.

57. Ezeoke CC, Morley JE. Pathophysiology of anorexia in the cancer cachexia syndrome. J Cachexia Sarcopenia Muscle 2015;6:287-302.

58. Amano K, Maeda I, Morita T, Baba M, Miura T, Hama T, Mori I, et al. C-reactive protein, symptoms and activity of daily living in patients with advanced cancer receiving palliative care. J Cachexia Sarcopenia Muscle 2017;8:457-465.

59. Morley JE, Little MO, Berg-Weger M. Rapid Geriatric Assessment: A tool for primary care physicians. J Am Med Dir Assoc 2017;18:195-199.

60. Morley JE. Anorexia of aging: Physiologic and pathologic. Am J Clin Nutr 1997;66:760-773. 